and changes in environmental variables (such as food density) are well known. Previously, comparative studies and optimality theory have addressed rather different kinds of ethological issue. The application of optimal foraging models to data on interspecies differences in territory size may throw light on the precise form of cross-species relationships, as well as demonstrating the complementarity of the two approaches.

Paul H. Harvey is a lecturer in the School of Biological Sciences, University of Sussex, Brighton BNI 9RH, and Georgina M. Mace is a research associate at London Zoo and at the Department of Anthropology, University College of London, London WCIE 6BT.

Atmospheric chemistry

\title{
First results from the Solar Mesosphere Explorer
}

\section{from Guy Brasseur}

THE first results from the Solar Mesosphere Explorer (SME), a satellite designed specially to study atmospheric ozone, are now becoming available (Geophys. Res. Lett. 10, 237; 1983). The results are of particular importance given the recent worries that chemical species produced by industrial and agricultural activity might affect atmospheric ozone concentrations. Ozone is present in the atmosphere only at a low concentration but plays a vital part in protecting the biosphere from the Sun's ultraviolet radiation.

Above an altitude of about $15 \mathrm{~km}$, ozone is produced from the photodissociation of molecular oxygen. In the stratosphere, its destruction is facilitated by nitrogen oxide and, to a lesser extent, by chlorine oxide, whose origin is partly anthropogenic. The study of stratospheric ozone is complicated because of atmospheric dynamics (general circulation, planetary waves and so on), which introduce a great variability in the measured concentrations and mask the effect of chemical reactions. In the mesosphere, however, the chemical time constants are sufficiently short that the ozone response to modification of the chemical or photochemical parameters should be almost immediate and practically independent of the dynamical conditions of the atmosphere. Furthermore, the mechanisms by which ozone is destroyed (established by Bates and Nicolet in 1950) are dependent only on the action of the hydrogen compounds $\mathrm{H}, \mathrm{OH}$ and $\mathrm{HO}_{2}$, which are themselves formed from water vapour.

The mesosphere therefore constitutes an ideal laboratory for the study of the chemical balance of ozone. The SME satellite, conceived at the Laboratory for Atmospheric and Space Physics of the University of Colorado, was launched into a polar orbit on 6 October 1981 . Since then, it has regularly reported data which are processed directly at the Boulder control centre within a few hours.

The first results of SME are of major importance. First, they clearly confirm that in the upper stratosphere and lower mesosphere, ozone concentration and temperature are inversely related, as foreseen by the Chapman theory in 1930 , and show that atmospheric temperature is the principal cause of changes in ozone density in the lower mesosphere. As the temperature decreases, the ozone density increases, and vice versa. In the vicinity of the stratopause $(50 \mathrm{~km})$, ozone is mainly lost through its recombination with atomic oxygen: $\mathrm{O}+\mathrm{O}_{3} \rightarrow 2 \mathrm{O}_{2}$, a reaction which has a direct temperature dependence and which therefore introduces an inverse dependence between ozone density and temperature.

Observations made by the SME limb scanning ultraviolet spectrometer between 48 and $66 \mathrm{~km}$ altitude ${ }^{1}$ and by the limb scanning infrared spectrometer between 50 and $90 \mathrm{~km}$ (ref. 2) show that the ozone concentration varies greatly in time and space and that its behaviour is closely related to atmospheric dynamics. Below $60 \mathrm{~km}$, a seasonal variation appears in the mixing ratio, with the largest values during the winter period, especially at high latitude. Above $80 \mathrm{~km}$ however, the mixing ratio maximum is formed near the summer pole.

Measurements in the region above the mesopause $(85 \mathrm{~km})$ also show a dramatic daily variation in ozone concentrations, suggesting rapid fluctuations in the atomic oxygen concentration caused by vertical motions transporting odd oxygen from above.

The density of nitrogen dioxide $\left(\mathrm{NO}_{2}\right)$ as well as the temperature have been inferred from measurements provided by a visible light spectrometer. The $\mathrm{NO}_{2}$ density ${ }^{3}$ varies from pole to pole and during the winter months exhibits considerable variability, reflecting the much larger degree of meridional movement of air in the winter stratosphere. The observations confirm that the periods of high $\mathrm{NO}_{2}$ at high latitudes occur when air flow is from the equator to the pole; low $\mathrm{NO}_{2}$ occurs when the flow is reversed. Oscillations in the meridional circulation are connected with sudden warmings in the spring highlatitude Northern Hemisphere.

The SME satellite also carries a spectrometer for measuring variations in the solar irradiance and a proton alarm system which can detect the precipitation of ener- getic particles - caused by a solar proton event ${ }^{4}$, for example. The largest event in the current solar cycle occurred on 13 July 1982, and the notable decrease of ozone concentration it caused was measured by SME. Proton events of this kind inject large numbers of high-energy protons into the middle atmosphere, changing the concentrations of ionized hydrogen, nitrogen and oxygen, and thus the ozone destruction rate and density. SME's near-infrared spectrometer observed ozone depletion reaching 70 per cent at $65^{\circ}$ latitude, $78 \mathrm{~km}$ altitude, on the morning side and $10-20$ per cent on the afternoon side.

All the observations, including those of the proton event, have been satisfactorily compared with a particularly elaborate two-dimensional model which takes into account most chemical reactions related to the mesosphere and the fundamental dynamical mechanisms $s^{5,6}$.

The enormous advance the SME satellite has made is to present an impressive series of data at different latitudes and for different seasons. Rapid processing of the primary data is enabling it to be effectively exploited. Measurements that are applied to the mesosphere will, however, have to be supplemented by programmes that study the stratosphere, where ozone chemistry is far more complicated. Stratospheric balloon measurement experiments and, in particular, the Balloon Intercomparison Campaign (BIC) sponsored by NASA, the Chemical Manufacturers Association and the Commission of the European Communities, are not limited to ozone data, but are also devoted to molecules such as $\mathrm{HCl}, \mathrm{HF}, \mathrm{HNO}_{3}, \mathrm{NO}$ and $\mathrm{NO}_{2}$ or radicals of the $\mathrm{OH}$ and $\mathrm{ClO}$ type. They remain important together with the ground-based and aircraft-borne measurements.

The BIC, conducted from the National Scientific Balloon Facility in Palestine, Texas, is intended to enable 17 scientific instruments, developed by teams from Canada, Europe, Japan and the United States, to perform almost simultaneous measurements up to $45 \mathrm{~km}$ altitude. Another campaign, called Global Budget of Trace Species (GLOBUS), will be held in September 1983. Its principal objective is to measure ozone and the nitrogen oxides, using a series of balloons which will be launched from the French base of Aire-surl'Adour. Complementary observations of stratospheric ions and aerosols will be performed, and should enable a determination of the stratospheric effects of the El Chichon volcano whose eruption in April 1982 injected a dust cloud very high into the atmosphere.

Guy Brasseur is at the Belgian Space Aeronomy Institute, B-1180 Brussels, and at the University of Brussels.

1. Rusch, D.W. et al, Geophys, Res, Lett. 10. 241 (1983)

2. Thoms, R.J. et al Geophys. Res. Lett 10, $245(1983)$

3. Mount, G.H. et al. Geophys Res. Lett. 10, 265 (1983).

3. Mount, G.H. et al. Geophys Res. Lett. 10, $265(1983)$.
4. Thomas, R.J. et al. Geophys. Res. Lett. 10, 253 (1983).

5. Solomon, S. et al. Geophys. Res. Lett. 10, 249 (1983).

6. Solomon, S. et al. Geophys. Res. Lett. 10, 257 (1983). 